\title{
Prostate cancer: to screen or not to screen?
}

\author{
It's happening, but the case has not been made
}

Cancer of the prostate is a common and important health problem. In 1978-82 in the European Community, with some geographical variations, the incidence amounted to 55 per 100000 , mortality 22.6 per 100000 , cumulative lifetime risk up to the age of 74 years $3.9 \%$, and cumulative mortality $1 \cdot 2 \%$. Of all cancers diagnosed in men, $13 \%$ are carcinomas of the prostate and $8.6 \%$ of all deaths due to cancer are caused by this disease. This amounts to 84889 new cases and 35084 deaths a year. ${ }^{1}$ Moreover, the incidence and mortality of prostate cancer are increasing faster than can be attributed simply to the increasing age of the population. One response to these statistics has been increasing demands for screening programmes. Is early detection possible and would early treatment help?

About $50-60 \%$ of all cases of prostate cancer in the European Community present with obvious metastases or are locally too advanced for potentially curative management. Of those cancers that seem to be limited to the prostate clinically, $25-35 \%$ will have lymph node metastases. ${ }^{2}$ Of the remainder, another $25-35 \%$ will be too advanced for curative treatment and will turn out to be unresectable if surgery is attempted. ${ }^{3}$ Those patients who present with metastatic disease and are treated with maximal endocrine treatment will have a median survival of 36 months. ${ }^{4}$ On the other hand, patients with locally confined but palpable disease who are treated by either radiotherapy or radical prostatectomy will show five year survival rates of $75-85 \%$ and will enjoy a life expectancy comparable to that of an aged matched male population. ${ }^{5}$ Against this background, therefore, it seems we should try to detect prostate cancer early and to reduce mortality by aggressive early management. This simplistic view is, however, untenable.

In two large and representative necropsy studies the cumulative incidence of prostate cancer over all ages was found to be $32 \cdot 9 \%$ and $18 \cdot 2 \%{ }^{7}$ If we take the $32 \cdot 9 \%$ found in Franks's study as representative and compare this prevalence figure with the yearly mortality in the European Community $-22 \cdot 6 / 100000$ - this suggests that only one in 1456 patients would die of prostate cancer. This calculation, often used in arguments about screening for prostate cancer by those critical of screening and early detection measures, does not, however, take lifetime risk into consideration. It is more realistic to compare the cumulative incidence at necropsy with the cumulative risk of detection of clinical cancer and the risk of dying from it up to the age of 75 . For the European Community these figures are: $32 \cdot 9 \%, 3.9 \%$, and
$1 \cdot 2 \%$ respectively (a ratio of $27: 3: 1$ ). Thus if all cancers discovered at necropsy were identified clinically and treated then 26 out of 27 patients would be treated unnecessarily because these tumours do not represent a threat to their lives. Even among men diagnosed as having clinical prostate cancer only one in three dies of the disease. However, a cut off at age 75 gives an unrealistic picture because those patients diagnosed at the age of 70-75 (the highest incidence) will die at 75-80. Across all age groups the ratio of incidence to mortality is two to one. The discrepancy results from many competing causes of death affecting this largely elderly population and to a low and slow rate of progression of many of the lesions, especially those found at necropsy.

The challenge therefore is to separate the pussycats from the tigers and identify aggressive tumours. Most (latent) carcinomas of the prostate found at necropsy are focal with a diameter of 1-2 mm and a volume of 0.005-0.05 ml. Tumours of this size are not identified clinically except incidentally in surgical specimens removed because of benign prostatic hyperplasia. Half of such incidental tumours are focal. The generally accepted policy is not to treat these tumours unless they are detected in a very young patient. ${ }^{7 \mathrm{a}}$ Tumours detected by digital rectal examination, through raised values of prostate specific antigen, or by transrectal ultrasonography are usually 4-7 $\mathrm{ml}$ in volume, and truly focal lesions are diagnosed in less than $4 \%$ of cases. The risk of identifying focal lesions on a large scale in any screening programme therefore seems negligible. ${ }^{8}$ The overall detection rate of one time screening is about $2 \cdot 5 \%$.

Once a carcinoma has been detected should it be treated? There are no valid randomised comparative studies of surveillance versus treatment. Historical comparisons between the results of the few surveillance studies of locally confined disease with results of treatment studies are not conclusive. Important prognostic factors such as T category, grade of differentiation, DNA ploidy, plasma values of prostate specific antigen, and age make comparisons difficult. Accordingly there are no great differences in cancer related and overall mortality between treatment and surveillance studies. This might be due to the ineffectiveness of treatment, to a slow rate of progression of tumours, to competing causes of death, or, most likely, to a combination of all these factors. Radiotherapy and radical prostatectomy are effective in treating locally confined prostate cancer. ${ }^{9}$ Clearly, therefore, some of the clinically detected locally confined tumours do not form an immediate threat to life. These tumours are, however, 
part of the lifetime incidence quoted above (3.9\%)-which suggests that overtreatment occurs in two of three patients.

The sensitivity, specificity, and positive predictive values of all three diagnostic tests (digital rectal examination, prostate specific antigen, and transrectal ultrasonography) are too low to justify their use. ${ }^{10}$ The use of each alone would result in many unnecessarily worried men and unwarranted prostate biopsies. Unfortunately we do not yet know the accuracy of the three tests in combination. The low specificity and positive predictive value is not, however, the only reason for not recommending the routine use of these tests. Early detection regimens should not be applied unless benefit is shown in terms of reduced mortality from cancer in randomised prospective trials. This is not the case.

There is, however, considerable pressure in many parts of the world to apply these methods as screening tests. Pressure comes from patients but also from doctors. In the United States the American Cancer Society and the American Urological Association recommend an annual rectal examination for men aged over 50. A recent survey has shown that most American urologists will also test for prostate specific antigen in any patient in that age group who walks into their office. ${ }^{11}$ In Germany population screening for prostate cancer has been a policy since 1978, and in Belgium an insurance supported annual check up includes a rectal examination.

Yet screening should not be recommended as public health policy until clear benefit in terms of reduced mortality from cancer can be shown in prospective screening studies. Such studies need to be carried out urgently, but in the meantime it seems that both public and profession are ready to accept a considerable possibility of overtreatment.

FRITZ H SCHRÖDER Chairman

Department of Urology,

Erasmus University,

Academic Hospital,

3015 GD Rotterdam,

Netherlands

1 Möller Jensen O, Esteve J, Möller H, Renard H. Cancer in the European Community and its member states. Eur F Cancer 1990;26:1167-256.

2 Donohue RE, Mani JH, Whitesel JA, Mohr S, Scanavino D, Augspurger RR, et al. Stage D1 adenocarcinoma of prostate. Urology 1984;23:118-21.

3 Van den Ouden D, Tribukait B, Blom JHM, Fossa SD, Kurth KH, Ten Kate FJW, et al. Deoxuribonucleic acid ploidy of core biopsies and metastatic lymph nodes of prostate cancer patients-impact on time to progression? $f$ Urol (in press)

4 Crawford ED, Eisenberger MA, Mcleod DG, Spaulding JP, Benson R, Dorr FA, et al. A controlled tria of leuprolide with and without flutamide in prostatic carcinoma. N Engl F Med 1989;321:419-24.

5 Gibbons RP, Correa RJ Jr, Brannen GE, Weissman RM. Total prostatectomy for clinically localized prostatic cancer: long-term results. $\mathcal{f}$ Urol 1989;141:564-6.

6 Franks LM. Latent carcinoma of the prostate. F Pathol Bacteriol 1954;68:603-16.

7 Gaynor EP. Zur Frage des Prostatakrebs. Virchows Arch 1938;301:602-52.

Walsh D, Patrick C. Radical prostatectomy in locally confined prostatic carcinoma. Proc Clin Biol Res 1990;359:199-207.

8 Scardino PT, Weaver R, Hudson MA. Early detection of prostate cancer. Human Pathol 1992;23:211-22.

9 National Cancer Institute. Consensus development conference on the management of clinically localized prostate cancer. Bethesda: NIH, 1988. (NCI Monograph 7.)

10 Bentvelsen FM, Schröder FH. Modalities available for screening for prostate cancer. Eur f Cancer (in press).

11 Thompson IM, Zeidman EJ. Current urological practice: routine urological examination and early detection of carcinoma of the prostate. $\mathcal{F}$ Urol 1992;148:326-9.

\title{
Waiting times for outpatient appointments
}

\author{
Time for ideas to come out of academe and into the clinic
}

As the financial year 1992-3 draws to a close some hospitals are already asking their doctors to stop admitting patients for elective surgery until the new financial year. This may limit the ability of these hospitals to meet their pledges of maximum inpatient waiting times of two years. The fact that some providers, including NHS trusts, have run out of money is not solely a problem of inefficiency or poor resource management (although it may be in some cases); it is also a reflection of the diversity and complexity of the demand for health care, which makes it so unpredictable. National guarantees cannot possibly take account of this variation, and standards can often only be met at a cost elsewhere. One of the worries about the limit on inpatient waiting times was that instead of tackling long waiting it would merely shift delays and patients would end up waiting longer for outpatient consultations.

Inpatient waiting times have long been the focus of attention, but for many patients waiting to be admitted to hospital is just the tip of a "waiting iceberg." British patients wait longer than most of their European neighbours to be seen by a hospital doctor, ${ }^{1}$ and for many the wait is not just weeks but months-months that may potentially make a great difference to their condition, as German et al show (p 429). ${ }^{\text {a }}$ Some women wait a year for a consultation with a gynaecologist.

The wait for an outpatient appointment is invisible. The NHS still lacks a systematic method of collecting information about outpatient waiting. The most commonly used statistic is average waiting time per specialty, but that figure varies with local definitions and is so skewed by interconsultant variation that it is virtually meaningless. Some regions do not produce even these data. Research too has overlooked outpatient waiting, concentrating instead on waits for inpatient procedures or general practitioner referral patterns. The publication of Waiting times for first outpatient appointments in the NHS, ${ }^{2}$ the report of a workshop commissioned by the Department of Health, therefore provides a timely reminder of the issues and offers some worthwhile solutions.

Reliable, up to date information about outpatient waiting times is essential. The report points out that most hospital computers could provide these data. We also need meaningful alternatives to measuring performance by averages, and the report argues that looking at centiles (for example, the time within which $90 \%$ of patients were seen) may give a better view of the situation. The report also urges greater communication, especially between consultants and general practitioners, not just about waiting times but about referral objectives and patient follow up too.

This is not the first time such suggestions have been made. Indeed, followers of the waiting list debate may experience déjà vu when reading this report. Back in 1978 the Department of Health and Social Security brought together clinicians, statisticians, health service researchers, economists, and civil servants for a similar seminar addressing waiting times for hospital treatment. ${ }^{3}$ Among the papers presented was a description of the "operations room" at the Ipswich Hospital (a Portakabin), whose staff held, coordinated, and above all, integrated information about waiting lists and waiting times. Wall charts and card indexes displayed data on inpatient waiting, new referrals, numbers waiting for an appointment, and waiting times for first non-urgent appointments as well as information on theatre availability and bed 